\title{
让中华文化融入到高中英语的课堂教学当中
}

\section{王金彦 雷艳}

湖南省安乡县第一中学

DOI:10.32629/jief.v2i6.952

[摘要] 随着时代教育走在国际的潮流之上, 英语也登上了国际化的舞台。英语是一种全球化通用的语言文化和交流方式, 对我们中国文化 也产生这很大的影响。对于高中阶段的英语课堂教学来说, 英语教学是为了培养学生们另一种交际应用的能力, 把中华文化和高中英语教学 融合, 是一种文化碰撞的方式, 能够让学生们发现两种文化的奥妙, 为学生未来的发展奠定良好的基础。

[关键词] 中华文化; 高中英语; 课堂教学的融合

中图分类号: G633.41 文献标识码: A

俗话说: “高中阶段是学生们人生的转折点”, 由此可见, 高中所 学到的知识体系, 能够影响学生们未来的发展。而英语这门面向世界的 语言知识体系, 作为一种文化形态, 在高中教育当中占着极其重要的地 位。在高中英语课堂教学当中, 教师为了确保教学的顺利开展以及良好 教学成果的产生, 就不仅仅要重视培养学生们能够实际性应用英语的能 力、词汇和语法的教学, 更要重视中华语言文化的教学。

\section{1 加强学生对词汇以及其文化内涵的理解}

随着高中英语教学在不断改革和创新, 教师应该加强自己对英语的 研究, 不断改进自身教学策略所存在的缺点, 找到适合当今时代发展和 学生们自身发展的教学方案。为了让学生们能够深入了解到英语这门学 科的文化底蕴, 就要和中华文化相结合, 产生文化和语言之间的亲切感。 而英语单词所表达出来的内涵和字面意识是存在着一定的差别的, 从中 就可以体会到汉字文化的英语结合起来的优美。因此, 在高中英语课堂 教学的过程当中, 教师既要让学生们不仅仅能掌握单词的字面意识, 更 能够深刻品味到单词所隐含的内涵。

例如: 当教师进行词汇的教学活动的时候, 老师先对学生们说: “今 天, 我们要进行英语词汇的教学, 老师会给你们很多个词汇组合而成的 短语, 先让你们自己从单个字意思的结合猜猜它们的总结意思, 最后你 们总结下你们猜的意思, 派个代表来说下。” 这时, 老师给出了: “blue stocking”, “dead president” “handwriting on the wa11”, “busybody”。 在学生们不断地探讨当中, 这时, 代表发言说: “老师我们觉得它们分 别的字面意识是: 蓝色长袜、已故总统、在墙上书写、大忙人、马的感 觉、谈论火鸡。” 老师笑着对学生们说: “分开来看, 你们都认识这些 词汇, 在你们看来, 从单个词汇的字面意识结合来说你们那样意思解释 是没问题的, 但是, 把中华文化和这些英语词汇结合在一起, 你就会发 现这里面存在的深层意思。老师给你们例子: “I know a blue stocking who spends most of her leisure time reading novels and attending plays”, 这句话是说认识一位有文学教养的人, 她一有时间就看小说和 参演戏剧, 这样你们就知道第一个词是 “才女、女学者” 的意思。第二 个例句: “she bummed a dead president off me”, 这句话的意思是 她向我讨了点美钞, 所以你们也可以看出来是美钞的意思。第三句: “I could see the handwriting on the wall when they called me in” 是说他们叫我进去的时候, 我感受到了不祥之兆, 而 “不祥之兆” 这个 解释就蒀含着深刻的中华文化。第四句: “This government is full of interfering busybodies” 是说这个政府里净是爱管闲事的人, 所以它 的意思是 “爱管闲事的人”。” 听完老师的讲解, 同学们发现中华文化 和英语融合, 所传达出来的意思是更美妙的。

\section{2 加强对学生习语文化内涵的教育}

习语是中华语言文化发展的结晶, 对中华文化和高中英语教学的融 合的促进起着很大的作用。老师加强学生们对习语的学习, 能够让学生 们在学习语言的时候, 能够掌握英语的文化, 并且从中也能感受到中华 文化的蕴意。汉语和英语是两个不同的语言体系, 它们的文化体系是存 在一定差异的。

例如: 在中华文化体系当中, “小菜一碟” 是表示在一个人看来某 件事情能够非常容易做到, 而对于在英语当中同样的一种习语是 “a piece of cake”, 可以解释为一碟碟子, 由此可见文化的差异, 因此, 教师可以通过节日和习俗等文化, 来加强习语文化内涵的教育。当老师 在讲高中英语必修四 unit 4 这一章节的时候, 因为有着很多跨文化的交 往, 老师就可以先给学生们讲解时间、节日文化、节日特色等等来了解 不同地方的不同文化, 老师对学生们说: 你们看这章说到了日本这个国 家, 他们问候的方式是互相鞠躬, 对于英国来说, 他们会保持人和人之 间应该有的距离。当学生们了解到不同文化, 他们在把中华文化和英语 结合的时候, 就会更好理解了。

\section{3 结语}

高中教育阶段, 是学生进一步提升的关键时期, 在这个阶段当中他 们所学到知识是很重要的。而中华文化从古至今, 在教育方面都有着长 远有深远的影响。所以, 不管是对高中英语教师还是学生他们自己而言, 都要深刻明确中华文化在教育这方面的造诣, 要紧密结合中华文化和高 中英语课堂教学。因此, 教师要尽自己的职责让中西文化发生灵魂深处 的碰撞, 打破中西文化上的交流阻碍, 成就学生们更广阔的未来。

\section{[参考文献]}

[1]苟荣萍.浅谈高考制度下高中英语教师角色的转变 [J].考试周 刊,2020(78):5-6.

[2]慈萌萌. 高中英语课堂教学开展名著品读活动的方法探究 [J]. 考 试周刊,2020(78):111-112.

[3]李晓琪,冀小婷.高中英语教学中 “看” 的技能与思维品质的培养 [J].天津师范大学学报(基础教育版),2020,21(04):44-47. 